\title{
A “amiga que já abortou": um olhar sobre experiências partilhadas em uma comunidade virtual
}

\author{
The "friend who has already aborted": A look at shared experiences \\ in a virtual community
}

Nanda Isele Gallas Duarte (https://orcid.org/0000-0003-4055-0878) ${ }^{1}$

Vera Lucia Marques da Silva (https://orcid.org/0000-0002-2595-2679) ${ }^{1}$

Liana Wernersbach Pinto (https://orcid.org/0000-0003-1928-9265) ${ }^{1}$

${ }^{1}$ Departamento de Estudos sobre Violência e Saúde Jorge Careli, Escola Nacional de Saúde Pública. Fundação Oswaldo Cruz. Av. Brasil 4036/7ㅇ, Manguinhos. 21040-210 Rio de Janeiro RJ Brasil.

nandaduarte@gmail.com

\begin{abstract}
The Brazilian research on abortion has pointed to the existence of a paradoxical dynamic about the event. If, on the one hand, it is a taboo subject surrounded by stigma, evidencing an apparent social invisibility of this practice, on the other hand, it is a common event in the reproductive life of women of all social classes, races, and religions, showing a culture of broad sharing of knowledge and practice on the subject. This paper is about the character of the "friend who has already aborted", which appears in narratives about the abortion experience shared publicly on an online platform, understood here as a virtual exchange community on the subject, maintained by the international NGO Women on Web. A virtual ethnography revealed that this person gains prominence in the narratives and the universe of the interpersonal social networks mobilized by women in its abortive course, relationships that stimulate reflection on the place of solidarity among women in the collectivization of knowledge and strategies and the production of a common resistance in the context of clandestinity and stigmatization underpinning the theme of abortion in the country. Key words Induced abortion, Social networks, Internet, Production of the commons
\end{abstract}

Resumo As pesquisas sobre aborto provocado no Brasil têm apontado para a existência de uma dinâmica paradoxal sobre o fenômeno. Se, por um lado, trata-se de um assunto tabu e cercado de estigma, conformando um tecido de aparente invisibilidade social para a prática, por outro é evento comum na vida reprodutiva das mulheres de todas as classes sociais, raças e religiões, indicando uma cultura de amplo compartilhamento de conhecimento e prática sobre o tema. Este artigo versa sobre a personagem da "amiga que já abortou", que aparece em narrativas sobre a experiência com aborto induzido compartilhadas publicamente em uma plataforma "online", entendida aqui como uma comunidade virtual de troca sobre o assunto, mantida pela organização não governamental internacional "Women on Web". A partir de uma etnografia virtual, percebeu-se que esta personagem ganha destaque nas narrativas e no universo das redes sociais interpessoais mobilizadas pelas mulheres no seu itinerário abortivo. Relações que estimulam a reflexão sobre o lugar da solidariedade entre mulheres na coletivização de saberes e estratégias e na produção de uma resistência comum diante do contexto de clandestinidade e estigmatização que conforma o tema do aborto no país.

Palavras-chave Aborto provocado, Redes sociais, Internet, Produção do comum 


\section{Introdução}

No Brasil, o aborto provocado é fenômeno comum na vida reprodutiva das mulheres ${ }^{1,2}$ ao mesmo tempo em que é cercado por silêncios e segredos $^{3,4}$. Um paradoxo que se faz presente nas narrativas que servem de objeto a este artigo: em uma comunidade virtual internacional, brasileiras partilham as histórias que têm em comum sobre aborto, num território em que é possível contar sua experiência sem colocar o segredo em risco.

O contexto que mantém a invisibilidade do tema do aborto no tecido social articula o peso da proibição legal - o aborto é crime no Brasil à exceção dos casos que envolvem risco de morte da gestante, gestação resultante de estupro e anencefalia fetal - ao estigma e a tabus culturais e morais vigentes ${ }^{5}$. O que Adesse e Monteiro ${ }^{6}$ chamam de "ciclo vicioso e perverso no qual a criminalização do aborto perpetua o estigma e, por sua vez, o estigma legitima a criminalização do aborto".

Os estudos sobre as condições que envolvem a realização de abortos induzidos têm apontado para os riscos que a criminalização representa para a saúde e a vida das mulheres que abor$\operatorname{tam}^{6-8}$, sobretudo as mulheres negras e em situação de vulnerabilidade econômica. O que localiza o tema do aborto como uma questão de Saúde Pública que diz respeito ao enfrentamento às desigualdades sociais, mais especificamente de gênero, raça e classe.

O repertório das estratégias que as mulheres desenvolvem para a realização do aborto é chamado pela literatura de itinerário abortivo: $o$ conjunto de métodos, recursos e informações e de relações sociais estabelecidas com familiares, amigos e amigas, vizinhos, profissionais de saúde, entre outros atores, ${ }^{910}$. É sobre este aspecto relacional dos itinerários abortivos que reside nosso interesse no presente artigo; sobretudo na relação de apoio mútuo que se estabelece entre mulheres durante sua mobilização para realizar um aborto e, especialmente, a interlocução com outras mulheres que já passaram por essa experiência. Para a análise destas relações, acionaremos especialmente duas abordagens da Saúde Coletiva que problematizam a tendência predominante que define cuidado em torno da oposição entre formal e informal ${ }^{11}$ : a perspectiva do cuidado reticular, que permite um olhar para o papel das redes sociais nas trajetórias dos sujeitos e seus processos de cuidado ${ }^{12}$, e a dimensão da "produção do comum" na saúde, que toma a coletivi- zação de saberes, meios e afetos como um "fazer comunidade" 12 .

O papel decisivo que a solidariedade feminina assume na adoção de estratégias frente às restrições legais e morais da prática do aborto indica a existência do que Diniz e Medeiros ${ }^{13}$ chamam de cultura do aborto compartilhada e transmitida entre diferentes gerações de mulheres. Assim, as tecnologias de informação e comunicação (TIC) que fomentam a sociabilização na internet, não inauguram, em si, o compartilhamento de informações e experiências, nem a articulação de recursos e dispositivos para a realização do aborto. Mas podem fornecer uma ampliação da capacidade de solidarização e mobilização de recursos das redes sociais ${ }^{14}$.

A discussão que apresentamos aqui se debruça sobre histórias de aborto induzido narradas publicamente em uma plataforma online, sobretudo sobre alguns de seus aspectos relacionais. Trata-se de um recorte dos resultados de pesquisa realizada no mestrado em Saúde Pública da Escola Nacional de Saúde Pública Sergio Arouca (ENSP-Fiocruz) entre 2017 e 2019.

\section{Sobre a plataforma online e sua escolha}

As narrativas que servem à análise deste artigo foram coletadas na plataforma online de troca de depoimentos sobre a experiência com a realização de um aborto chamada "Fiz um aborto", que integra o portal do grupo Women on Web (WoW). Trata-se de um mapeamento de histórias sobre aborto, seja legal ou ilegal, de usuárias de 151 países. Os depoimentos são disponibilizados através do preenchimento de um formulário com diversos campos. Os critérios para a escolha deste portal para o campo incluíram a sua relevância (um dos três principais resultados, em 2017, entre espaços virtuais de compartilhamento público de histórias sobre aborto), a facilidade de navegação (as histórias são disponibilizadas em um mural que lembra um aplicativo com avatares), o grande número de depoimentos oriundos do Brasil e o fato de informar publicamente as organizações que mantêm o projeto (o que facilitou a verificação de informações e o contato para entrevistas).

Fundado em 2005, o site do WoW é a continuidade, na internet, do ativismo da ONG holandesa Women on Waves. Desde 1999, a equipe da organização navega com um grupo de médicos pela costa de países onde o aborto é ilegal, oferecendo aborto medicinal a mulheres que a procuram, valendo-se da regra da navegação em águas internacionais, regida pela lei do país de 
origem da embarcação - no caso, um país em que o aborto é permitido desde $1981^{15}$. Braço digital da ONG, o site Women on Web mantém canais de telemedicina, em onze línguas, que orientam por e-mail, chat ou telefone sobre como realizar aborto com medicamentos e, em muitos casos, enviam remédios abortivos pelo correio a países onde eles são ilegais ${ }^{16}$. Para as brasileiras, no entanto, uma mensagem em destaque informa que a alfândega do país retém os pacotes enviados pela organização.

Neste trabalho, a análise se deterá ao projeto "Fiz um aborto" e suas histórias, que se encontram disponíveis publicamente no site. Elas estão agrupadas por país de origem - em 5 de novembro de 2018, 17 relatos eram do Irã; 73 da Nigéria; 357 da Argentina; 434 do México; 467 dos Estados Unidos; 794 da Polônia e 1.086 do Brasil.

\section{Observação e coleta de dados}

Realizamos uma pesquisa de cunho qualitativo, utilizando etnografia virtual, entrevista e análise de narrativa. Para Hine ${ }^{17}$, a etnografia virtual pode ser mobilizada para alcançar os significados da tecnologia e das culturas que a estruturam, ao mesmo tempo em que são estruturadas por ela. O desenho metodológico foi inspirado no trabalho de Miller e Slater ${ }^{18}$, que reconhece este relacionamento complexo e nuançado entre os mundos online e offline, sem separar a internet, como uma tecnologia, do processo de troca. Assim, as etapas da etnografia virtual empreendida incluíram a observação da interação na plataforma do Women on Web, de abril a dezembro de 2018, a coleta de 22 narrativas compartilhadas para análise, sobre as quais nos deteremos neste artigo, a realização de entrevista com representante da ONG que mantém o espaço, e a análise de entrevistas e outros materiais disponíveis publicamente sobre a organização.

Para a coleta das narrativas, lançamos mão dos filtros disponíveis na própria plataforma, sobretudo aquele que classifica as histórias segundo os sentimentos reivindicados pelas mulheres para a experiência. Escolhemos uma história entre cada uma das 22 possibilidades de classificação dos sentimentos (de “aliviada" à “zangada”), a fim de garantir certa diversidade de percepções que caracteriza a troca entre as usuárias do site. Em que pese o livre acesso ao material e a possibilidade de utilização de apelidos na plataforma, buscamos sobrepor mecanismos de proteção à identificação das autoras, atribuindo novos e diferentes codinomes.

\section{Localizando as narrativas: apontamentos sobre o perfil das autoras}

A fim de localizar os lugares de fala de que partem as narrativas, buscamos identificar elementos socioeconômicos, culturais e outras características a partir de como elas se apresentam em seus textos. Lugar de fala é entendido aqui, conforme a elaboração de Djamila Ribeiro ${ }^{19}$, como uma forma de entender os contextos sociais que condicionam e influenciam experiências e o modo como são narradas, possibilitando a reflexão sobre as condições sociais que permitem ou não que determinados grupos acessem lugares de cidadania.

Algumas informações foram facilitadas pela própria plataforma: o formulário de upload das histórias já indaga sobre idade, religião e a existência de filhos/as, por exemplo. Para outras, foi preciso apreender os dados na leitura de cada narrativa, como a situação relacional, ocupacional e informações que ajudassem a compreender o contexto social e econômico em que a história está inserida. Uma característica comum a todos os relatos diz respeito ao território. Trata-se de um Brasil urbano, a partir de onde elas contam com acesso a tecnologias de informação e comunicação, nível de médio a alto de escolaridade, serviços de saúde de médio e grande porte e redes sociais variadas. Esta caracterização está resumidamente organizada no Quadro 1.

Os textos informam sobre um perfil preponderantemente jovem, de camadas médias/baixas, sendo a maioria cristã e sem filhos. Das 22, 16 informam a idade e têm entre 19 e 29 anos, duas mencionam serem "novas" e uma “jovem", e apenas três não informam esse dado nem indiretamente. Em relação à religião, a maioria é cristã (13), uma espírita, uma de religião de matriz africana, duas marcaram a opção "outra religião" e cinco dizem não ter religião. Sobre relacionamento, nove namoram, três são casadas, nove não têm parceiro fixo (sendo duas divorciadas) e uma não informa a respeito. Sete são estudantes (ensino médio e superior), quatro estão desempregadas, cinco trabalham e em sete narrativas não há informação muito clara sobre ocupação. A maior parte menciona problemas financeiros (14), uma se diz de "baixa renda" e sete não mencionam questões de ordem financeira. Quatro já são mães.

A Pesquisa Nacional do Aborto ${ }^{1,2}$ indica que a interrupção voluntária da gravidez é um evento comum na vida de mulheres de todas as classes sociais, idades e religiões. Outras pesquisas con- 
Quadro 1. Quadro da caracterização das autoras das narrativas.

\begin{tabular}{|c|c|c|c|c|c|c|c|}
\hline $\begin{array}{c}\text { Nome } \\
\text { (sentimento de } \\
\text { "referência") }\end{array}$ & Idade & $\begin{array}{l}\text { Situação } \\
\text { relacional }\end{array}$ & $\begin{array}{c}\text { Tem } \\
\text { filhos/ } \\
\text { as? }\end{array}$ & Moradia & $\begin{array}{c}\text { Situação } \\
\text { ocupacional }\end{array}$ & $\begin{array}{l}\text { Informações } \\
\text { econômicas }\end{array}$ & Religião \\
\hline Aline (aliviada) & 19 anos & Namorando & Não & $\begin{array}{c}\text { Com os } \\
\text { pais }\end{array}$ & Estudante & $\begin{array}{l}\text { Problemas } \\
\text { financeiros }\end{array}$ & Cristã \\
\hline Patrícia (apática) & 23 anos & $\begin{array}{l}\text { Solteira sem } \\
\text { parceiro fixo }\end{array}$ & Não & $\begin{array}{c}\text { Com } \\
\text { amigas }\end{array}$ & Desempregada & $\begin{array}{c}\text { Baixa renda/ } \\
\text { formação } \\
\text { incompleta }\end{array}$ & Espírita \\
\hline Cora (confiante) & 23 anos & Casada & Não & $\begin{array}{c}\text { Com o } \\
\text { parceiro }\end{array}$ & - & - & $\begin{array}{c}\text { Sem } \\
\text { religião }\end{array}$ \\
\hline Cátia (confortável) & 24 anos & Namorando & Não & - & Estudante & - & Cristã \\
\hline Carolina (confusa) & 26 anos & - & Sim & - & $\begin{array}{l}\text { Trabalha (área } \\
\text { da saúde) }\end{array}$ & $\begin{array}{l}\text { Problemas } \\
\text { financeiros }\end{array}$ & $\begin{array}{c}\text { Sem } \\
\text { religião }\end{array}$ \\
\hline Daniela (culpada) & 29 anos & $\begin{array}{l}\text { Solteira sem } \\
\text { parceiro fixo }\end{array}$ & Não & $\begin{array}{c}\text { Com os } \\
\text { pais }\end{array}$ & Desempregada & $\begin{array}{l}\text { Problemas } \\
\text { financeiros }\end{array}$ & $\begin{array}{c}\text { Matriz } \\
\text { africana }\end{array}$ \\
\hline Luna (de luto) & - & Casada & Sim & $\begin{array}{c}\text { Com o } \\
\text { parceiro }\end{array}$ & $\begin{array}{c}\text { Estudante } \\
\text { universitária }\end{array}$ & $\begin{array}{l}\text { Problemas } \\
\text { financeiros }\end{array}$ & Cristã \\
\hline Débora (decidida) & - & Namorando & Não & - & Trabalha & $\begin{array}{l}\text { Momento } \\
\text { financeiro } \\
\text { complicado }\end{array}$ & Outra \\
\hline $\begin{array}{c}\text { Daiane } \\
\text { (desapontada) }\end{array}$ & 28 anos & $\begin{array}{c}\text { Divorciada, } \\
\text { sem parceiro } \\
\text { fixo }\end{array}$ & Sim & - & - & $\begin{array}{c}\text { Situação } \\
\text { financeira } \\
\text { "decadente" }\end{array}$ & $\begin{array}{c}\text { Sem } \\
\text { religião }\end{array}$ \\
\hline Elaine (egoísta) & - & $\begin{array}{l}\text { Solteira sem } \\
\text { parceiro fixo }\end{array}$ & Não & $\begin{array}{c}\text { Com o } \\
\text { pai }\end{array}$ & $\begin{array}{c}\text { Estudante / } \\
\text { desempregada }\end{array}$ & $\begin{array}{l}\text { Problemas } \\
\text { financeiros }\end{array}$ & Cristã \\
\hline $\begin{array}{c}\text { Gisele } \\
\text { (encurralada) }\end{array}$ & - & $\begin{array}{l}\text { Solteira sem } \\
\text { parceiro fixo }\end{array}$ & Não & Sozinha & - & - & Cristã \\
\hline $\begin{array}{c}\text { Fernanda } \\
\text { (envergonhada) }\end{array}$ & 20 anos & Namorando & Não & - & $\begin{array}{c}\text { Estudante } \\
\text { universitária }\end{array}$ & $\begin{array}{l}\text { Menciona uma } \\
\text { vida "cômoda" }\end{array}$ & $\begin{array}{c}\text { Sem } \\
\text { religião }\end{array}$ \\
\hline Laura (estúpida) & "Jovem" & Namorando & Não & - & $\begin{array}{c}\text { Trabalha } \\
\text { / estudos } \\
\text { incompletos }\end{array}$ & $\begin{array}{l}\text { Problemas } \\
\text { financeiros }\end{array}$ & Cristã \\
\hline Graça (feliz) & 23 anos & $\begin{array}{l}\text { Solteira sem } \\
\text { parceiro fixo }\end{array}$ & Não & $\begin{array}{c}\text { Com os } \\
\text { pais }\end{array}$ & - & - & Cristã \\
\hline $\begin{array}{c}\text { Priscila } \\
\text { (irresponsável) }\end{array}$ & 21 anos & $\begin{array}{l}\text { Solteira sem } \\
\text { parceiro fixo }\end{array}$ & Não & $\begin{array}{l}\text { Com a } \\
\text { mãe }\end{array}$ & $\begin{array}{c}\text { Trabalha / } \\
\text { Estudante } \\
\text { universitária }\end{array}$ & - & Cristã \\
\hline Nádia (na dúvida) & 20 anos & $\begin{array}{l}\text { Namorando } \\
\text { (noiva) }\end{array}$ & Não & - & $\begin{array}{l}\text { Trabalha } \\
\text { (menção ao } \\
\text { "serviço") }\end{array}$ & $\begin{array}{l}\text { Problemas } \\
\text { financeiros }\end{array}$ & Cristã \\
\hline Paula (normal) & 19 anos & Namorando & Não & $\begin{array}{c}\text { Com o } \\
\text { parceiro }\end{array}$ & - & $\begin{array}{c}\text { Situação } \\
\text { financeira } \\
\text { difícil }\end{array}$ & Cristã \\
\hline Raquel (receosa) & 23 anos & Casada & Não & $\begin{array}{c}\text { Com o } \\
\text { parceiro }\end{array}$ & - & $\begin{array}{l}\text { Problemas } \\
\text { financeiros }\end{array}$ & Cristã \\
\hline Teresa (segura) & 21 anos & $\begin{array}{l}\text { Solteira sem } \\
\text { parceiro fixo }\end{array}$ & Sim & $\begin{array}{c}\text { Com os } \\
\text { pais }\end{array}$ & & $\begin{array}{l}\text { Problemas } \\
\text { financeiros }\end{array}$ & Cristã \\
\hline Serena (serena) & "Nova" & Namorando & Não & - & - & - & $\begin{array}{c}\text { Sem } \\
\text { religião }\end{array}$ \\
\hline Tatiana (triste) & "Nova" & Namorando & Não & - & $\begin{array}{l}\text { Trabalha } \\
\text { (menção ao } \\
\text { “serviço") }\end{array}$ & $\begin{array}{l}\text { Problemas } \\
\text { financeiros }\end{array}$ & Cristã \\
\hline Zuleica (zangada) & 26 anos & Namorando & Não & - & Autônoma & $\begin{array}{l}\text { Problemas } \\
\text { financeiros }\end{array}$ & Outra \\
\hline
\end{tabular}


centram-se em populações específicas, considerando, frequentemente, mulheres admitidas em hospitais públicos com aborto incompleto, o que pode ser considerado um viés de seleção ${ }^{20}$, uma vez que consideram apenas a parcela dos abortos que necessitam hospitalização por complicação. De forma análoga, para esta pesquisa, era esperado que o grupo analisado reportasse um recorte etário jovem, uma vez que a população jovem é a maior usuária de internet no Brasil, segundo a Pesquisa Nacional por Amostra de Domicílios $(\mathrm{PNAD})^{21}$. Assim, a expectativa era a de que este "viés de seleção" pudesse gerar uma certa homogeneidade dos perfis e das experiências. Isso se confirma em relação a algumas características mais comuns no grupo: mulheres jovens, maioria sem filhos e de territórios urbanos. Mas não o suficiente para considerar o grupo homogêneo: há uma diversidade em relação à ocupação, à situação de moradia, à situação conjugal e econômica, ainda que dentro de uma margem e frente à escassez de dados mais precisos a respeito da condição socioeconômica. Uma ausência sentida na caracterização do grupo diz respeito à raça/ etnia: o formulário do site não inclui esta pergunta e, nos textos analisados, esse elemento não é mencionado espontaneamente, o que impede a discussão sobre as intersecções entre gênero, raça e classe neste trabalho. Consideramos uma limitação digna de nota porque o debate sobre aborto no Brasil e, especialmente, sobre os efeitos da criminalização do aborto, passa necessariamente pela discussão do racismo estrutural: pesquisas mostram que as mulheres negras morrem mais por complicações de abortos inseguros ${ }^{22}$, são mais processadas pela realização de abortos clandestinos $^{23}$ e enfrentam mais barreiras institucionais no acesso a serviços de saúde após o abortamento $^{24}$.

\section{Solidariedade feminina em rede: "Se não fosse por ela, estaria praticamente perdida"}

Os itinerários abortivos descritos nos relatos envolvem a mobilização de parceiros, familiares, amigos, ONGs e grupos feministas de apoio, seja na internet ou fora dela, serviços formais de saúde e profissionais de saúde que atendem clandestinamente, além dos fornecedores de medicamento abortivo, o principal método utilizado no grupo. Articulam, assim, a esfera das solidariedades primárias ou redes sociais primárias (relações de familiaridade, parentesco, vizinhança, amizade) e secundárias (grupos, organizações e movimentos que defendem interesses comuns e/ ou partilham conhecimentos para determinados fins $)^{11}$.

Quando identificamos, nas narrativas, os personagens que integram as redes primárias acionadas, as mulheres ocupam lugar de destaque. Muitas amigas e algumas mães e tias são citadas como personagens-chave nas narrativas, seja pelo apoio emocional que fornecem, pela confiança que as habilita ao papel de confidentes ou pela companhia solidária no momento da realização do aborto ou da busca por serviços de saúde. É o caso de Daiane, que diante de uma gravidez imprevista e sem condições nem desejo de levá -la adiante, contou com a ajuda de sua mãe e de uma amiga, ainda que elas não fossem favoráveis ao aborto. Ela escreve, em um fluxo contínuo de texto sem pontuação, ao mesmo tempo culpada e grata, que após fazer uso da medicação, enquanto sentia os sintomas do abortamento, se sentiu ... despedaçada por dentro por minha mãe me ver fazendo uma coisa tão abominável e ainda assim me apoiando mesmo sendo evangélica ela me abraçou mas não chorou perguntou se eu estava bem, se estava tudo correndo bem. Ardaillon sublinha que a decisão de abortar é sempre a resultante de negociações entre ideologia, realidade social e desejo, que conforma a "moralidade da situação”, em muitos casos resumível pela frase: "estou dizendo que o aborto é moralmente mau, mas que a situação é correta, e eu vou fazê-lo", encontrada, sob diversas variantes, em estudos tanto com mulheres de classe média, como com mulheres de camadas populares ${ }^{25}$. A narrativa de Daiane veicula essa negociação e dá sinais de que sua mãe e sua amiga também aderiram à moralidade da situação, negociando com suas crenças um espaço para apoiá-la em sua decisão.

A mãe também é figura importante na história de Paula, que, apesar de cristã como muitas outras, desenvolve uma narrativa pragmática sem evocação de sentimento de culpa: Quando entrei na $6^{a}$ semana resolvi contar pra minha mãe que no momento está nos EUA, ela me deu total apoio, disse que estava totalmente certa em abortar. Resolvi contar pra minha tia (que também me apoiou) e ela conhecia um amigo que vendia Cytotec.

Já a narrativa de Daniela tem diversas personagens femininas marcantes. Uma delas é a amiga M., que a acompanhou no processo: Minha amiga acompanhou tudo. Segurando minha mão. Me deu banho e me levantou do chão várias vezes. Nunca vou esquecer isso.

Nessa troca de informações, saberes e apoio em que as mulheres ocupam lugar privilegiado nas narrativas, uma personagem recorrente cha- 
ma a atenção: aquela pessoa que já passou pela experiência de provocar um aborto. Nas histórias de Aline, Catia, Carolina, Laura, Graça, Priscila, Nadia, Teresa e Zuleica, esta personagem aparece em algum momento, seja na pele de uma amiga, tia, prima, vizinha, conhecida ou até mesmo uma desconhecida que acaba sendo alçada ao status de nova amiga. Neste trabalho, chamamos esta personagem-chave de "a amiga que já abortou".

$O$ papel central que essa personagem cumpre em algumas histórias fica bem exemplificado na narrativa de Carolina. Inicialmente sem recursos para adquirir o medicamento, contou com a ajuda de uma conhecida que diziam sobre ela ter abortado e possuía ainda sobras do medicamento, comprimidos de misoprostol não utilizados. Essa primeira tentativa foi infrutífera e, sem dinheiro para adquirir o medicamento no mercado clandestino, Carolina se viu "arrasada", "engoliu o orgulho" e pediu dinheiro emprestado a uma amiga, a quem tinha "como irmã". Foi, no entanto, surpreendida pelo desprezo dessa amiga, que a "enrolou" e não emprestou o dinheiro. Em pânico, com oito semanas de gestação e vendo o tempo passar sem encontrar a solução que buscava, ela se desesperou:

E eu tinha medo de o tempo passar, o feto crescer e não ter mais tempo. Me desesperei tanto, bebi horrores neste dia. E quando eu menos esperava, um anjo bom me apareceu. Uma pessoa desconhecida que me foi apresentada e havia passado pela mesma situação, porém com um fim horrível [...] e ela me ajudou.

Com o dinheiro emprestado desse "anjo bom", com quem criou uma amizade posterior, Carolina comprou mais misoprostol e deu continuidade à sua jornada. $\mathrm{O}$ auxílio ao acesso ao método, compartilhando recursos e informações, é uma das contribuições da "amiga que já abortou” nas narrativas. Dada a instabilidade do contexto da clandestinidade, porém, nem sempre esse conhecimento prévio se mantém como alternativa. Catia, por exemplo, ao chegar na cidade de uma prima que já havia interrompido uma gravidez, descobre que a clínica que buscava a partir da indicação dela havia sido fechada pela polícia.

Em algumas narrativas, a mediação da internet para essa troca de informações e apoio entre mulheres ganha ainda mais centralidade, confirmando a contribuição das tecnologias de informação e comunicação para a ampliação da capacidade de solidarização e mobilização de recursos das redes sociais, conforme assinalado por Castells $^{15}$. É o caso da estudante de 19 anos Aline, que "fez amizade" na rede com uma mulher que já havia abortado, que lhe passou dicas e o contato que ela utilizou para a compra do medicamento. Se não fosse por ela, estaria praticamente perdida, decretou em seu texto.

A solidariedade feminina é conhecida na literatura sobre aborto: a transmissão de saberes sobre práticas e métodos, o acompanhamento e a partilha do segredo entre mulheres têm caracterizado as redes de proteção mobilizadas nos itinerários abortivos das brasileiras ${ }^{13,26-28}$. Cabe ressaltar também a configuração reticular das trocas que se estabelecem entre as mulheres, online e offline. A atenção para a importância das redes sociais na resolução dos itinerários abortivos nos permite pensar, junto com Portugal ${ }^{11}$, sobre a articulação do conceito de rede com o de cuidado, que revela a complexidade de conexões entre atores públicos e privados e a heterogeneidade de relações e de fluxos formais e informais. Ao realizar esta articulação, a autora propõe um olhar sobre a forma e o conteúdo das relações sociais que se estabelecem, em especial os laços da rede ${ }^{11}$. Em nossa análise, a "amiga que já abortou” se revela um destes laços, um "nó” importante na rede mobilizada pelas mulheres. E, ao dividirem suas histórias na plataforma, estas mulheres tornamse também um "nó”, um laço, um encontro na rede de outras, as suas leitoras. Esta possibilidade se expressa nas narrativas especialmente de duas formas: como reconhecimento da importância que a leitura de outras histórias significou nos seus percursos e na intenção de reproduzir nos seus relatos o detalhamento de métodos, doses, sintomas e dicas. Esta maneira quase prescritiva de comunicar as inúmeras experiências de interrupção de uma gravidez transforma o espaço da plataforma em uma grande partilha de modos de fazer, que são singulares em muitos aspectos, mas que narram uma experiência comum ao mesmo tempo em que coletivizam estratégias também comuns.

\section{Os dois fluxos do comum: "Eu passei pelo mesmo que você! Calma, que dará tudo certo!"}

A experiência compartilhada é, portanto, o centro da interação das mulheres na plataforma. Na relação que estabelecem por meio de troca de narrativas, identificamos dois movimentos que se encontram relacionados:

1) A valorização da experiência comum como um ponto de conexão entre histórias diversas. $\mathrm{O}$ depoimento de Graça é exemplar sobre esse aspecto: 
voltei a procurar na internet e li todos os depoimentos que encontrei, precisava de ajuda e incentivo. Ler vários casos que deram certo foi fundamental, mesmo sem fazer ideia de como eram aquelas pessoas, elas me proporcionaram um conforto e me incentivaram como nenhuma outra pessoa conhecida poderia fazer.

Zuleica finaliza seu relato agradecendo a partilha de outras mulheres, enumerando singularidades e diferenças entre elas, mas sublinhando que o seu entendimento sobre a própria experiência foi influenciado e facilitado pelas outras mulheres:

Não tenho como agradecer o suficiente toda segurança que senti aqui. Agradeço imensamente também a cada uma das mulheres que contou sua história, desde as que queriam, as que não queriam fazer o aborto, as mais novas, as mais velhas, as que tinham certeza, as que não tinham, as que tiveram muitas complicações, as que não tiveram. Todo relato é válido e bem vindo. Eu sabia tudo que poderia ou não acontecer comigo, graças a vocês! Obrigada corajosas!

Já a fala de Daiane revela a compreensão da experiência que viveu como algo que caracteriza sua condição de mulher e a relação entre a ilegalidade da prática com a injustiça social marcada pelo gênero.

e deixo aqui meu depoimento a tantas e tantas outras Marias que passaram e passarão por isso uma vez ou outra na vida, muitas das vezes pelo peso de ser MULHER, passou comigo e você em seu momento de desespero também passará apenas desejo do fundo do coração que as que forem passar como passei em casa por meio de medicamentos passem amparadas de amor e que corra tudo bem como aconteceu comigo ... beijo e abraço a todas... nós que somos ilegais em um país tão injusto com a nossa raça MULHERES...

Note-se que o peso de ser mulher veicula a condição de subalternidade comum à experiência das mulheres, enquanto o uso da palavra "amparada", contrapondo-se ao desamparo associado à subalternidade, sinaliza união entre Daiane $e$ as demais.

O reconhecimento da experiência comum como um marcador da percepção sobre ser mulher em um dado contexto histórico foi abordado por Camurça ${ }^{29}$. Ao estudar a partilha e a análise de biografias entre um grupo de pesquisadoras-educandas, a autora aponta que elas "percebem-se mulher e compreendem o ser mulher como uma experiência socialmente compartilhada e historicamente situada, ainda que seja uma experiência singular para cada uma". Assim, estas experiências comuns, quando reconhecidas, fornecem significados sobre as práticas sociais que contextualizam as "formas sociais do lidar com a menstruação e a puberdade das meninas, [...] a dupla jornada" $29 \mathrm{e}$, pensamos aqui, a questão do aborto.

2) A coletivização de aprendizados e estratégias como forma de produção do comum, a começar pela escrita dirigida a uma leitora, que marca a intenção de falar diretamente a alguém que no futuro pode estar partilhando das mesmas dúvidas e angústias que elas experimentaram. Foi o que fez Gisele: Bom, vou contar desde o início pq quero compartilhar cada momento da minha experiência e cada detalhe pq sei que irá ajudar mais pessoas que estão passando por essa situação. Esta preocupação em ser minuciosa também é revelada por Paula: Minha história é grande mas preciso relatar os detalhes para outras mulheres terem o máximo de entendimento possivel. As narrativas transmitem assim uma necessidade de "retribuição" ao ciclo que as beneficiou no seu processo, como se elas pudessem se tornar, ao dividir sua experiência ali, a "amiga que já abortou" de alguma mulher desconhecida.

Dessa forma, para além dos efeitos do reconhecimento de uma experiência comum, interessa refletir sobre a partilha, a intenção de dividir esta experiência. Silvia Federici ${ }^{30}$ analisou a coletivização do trabalho reprodutivo, que ela chama de produção do "comum" pelas mulheres, como forma de resistência à exploração e à divisão sexual do trabalho no capitalismo, em que um elemento central é a solidariedade com quem partilha destes comuns. Analogamente, é possível pensar sobre o compartilhamento da experiência comum entre as mulheres na plataforma do Women on Web como ferramenta de resistência ao contexto de clandestinidade, estigmatização e controle sobre seus corpos, sendo a solidariedade um princípio norteador das relações que se estabelecem entre elas, suas "amigas que já abortaram" e as desconhecidas que ainda irão abortar.

Resistência aqui tem o sentido proposto por Soihet ${ }^{31}$, com atenção especial aos "papéis informais, visíveis apenas através do enfoque do cotidiano" como recurso para a obtenção de pistas que possibilitem a reconstrução da "experiência concreta das mulheres em sociedade, que no processo relacional complexo e contraditório com os homens têm desempenhado um papel ativo na criação de sua própria história"31. Uma perspectiva que articula vivência e criatividade como práxis centrais ao entendimento sobre as resistências. Em algumas das narrativas abordadas nessa seção, estes são elementos que se en- 
contram vinculados: o ponto de partida de uma experiência comum e a produção, a partir dele, de uma partilha, uma coletivização de estratégias, saberes e solidariedade que produz um "comum" $(\text { commons })^{30}$.

Retomando a abordagem de Teixeira, que aproxima a produção do comum de "fazer comunidade"12, a origem do termo commons remonta aos campos e florestas que eram compartilhados na Europa pré-capitalista e foram alvo de cercamento e expropriação pelos Estados Nações, quando de sua formação. A alusão a essa territorialidade de partilha que fora expropriada e que volta a ser reivindicada e construída de alguma forma tem sido acionada para pensar a criação a partir das resistências como "produção do comum" ${ }^{12,30}$. Uma abordagem útil para refletirmos sobre o caso em análise. O exercício de partilha das mulheres autoras das narrativas produz um comum como estratégia de vida, resistindo e buscando minimizar a alienação em relação aos saberes sobre o aborto gerada pelo contexto de clandestinidade, pelo estigma social e pela expropriação histórica que a medicina realizou ${ }^{32}$ do conhecimento das mulheres sobre seu corpo.

\section{Considerações finais}

Os aspectos relacionais que integram os itinerários abortivos narrados por brasileiras no portal do grupo Women on Web se apresentam de forma reticular, envolvendo redes sociais primárias e secundárias. Frente às lacunas das políticas públicas para uma assistência humanizada ao abortamento, ao estigma social em relação ao tema do aborto e aos riscos da clandestinidade a que es- tão submetidas, as mulheres se movimentam em rede, contando especialmente com outras mulheres para resistir às tensões do contexto. Nas redes primárias acionadas em seus itinerários, uma personagem desponta em importância como buscamos demonstrar: a "amiga que já abortou".

As trocas com esta personagem são caracterizadas por apoio moral, informações, partilha de recursos e empatia por uma situação já vivenciada. Estes elementos também são comuns à relação entre as mulheres e os depoimentos lidos, o que estimula muitas delas a retribuir o gesto de que se beneficiaram, compartilhando também suas histórias e aprendizados. Assim, no ambiente da plataforma, elas intencionam tornarem-se também a "amiga que já abortou" de outras mulheres, desconhecidas, que poderão ler seus relatos.

A experiência comum compartilhada é, junto com o cuidado reticular e a solidariedade, uma categoria central à interpretação da interação das mulheres na plataforma. Na relação que estabelecem, evidenciamos dois movimentos: 1) o reconhecimento de que estão conectadas por uma experiência socialmente compartilhada e 2) a coletivização de estratégias comuns para lidar com as dificuldades desta experiência.

As redes de solidariedade conectadas pela vivência e pela partilha comuns podem ser pensadas como fissuras em movimento frente ao ciclo vicioso perpetrado pela criminalização e estigmatização do aborto no Brasil. Podem, ainda, inspirar o campo da Saúde Coletiva a fomentar políticas públicas que considerem as dimensões relacionais e reticulares da cultura do aborto compartilhada, valorizando a experiência das mulheres no enfrentamento às desigualdades de gênero. 


\section{Colaboradores}

NIG Duarte é responsável pela concepção, coleta e interpretação dos dados, escrita da redação do texto. VLM Silva e LW Pinto são responsáveis pela orientação, interpretação dos dados e revisão do texto.

\section{Referências}

1. Diniz D, Medeiros M. Aborto no Brasil: uma pesquisa domiciliar com técnica de urna. Cien Saude Colet 2010; 15(Supl. 1):959-966.

2. Diniz D, Medeiros M, Madeiro A. Pesquisa Nacional de Aborto 2016. Cien Saude Colet 2017; 22(2):653660.

3. Motta FM. Sonoro silêncio: por uma história etnográfica do aborto. Revista Estudos Feministas 2008; 16(2):681-689.

4. Porto RM. Aborto Legal e cultivo ao segredo. Dramas, práticas e representações de profissionais de saúde, feministas e agentes sociais no Brasil e em Portugal [tese]. Florianópolis: Universidade Federal de Santa Catarina; 2009.

5. Scavone L. Políticas feministas do aborto. Rev Estud Fem 2008; 16(2):675-680.

6. Adesse L, Monteiro MFG. Estigma e complicações do abortamento induzido. In: Zanello V, Porto M, organizadores. Aborto e (não) desejo de maternidade(s):questões para a Psicologia. Brasília: Conselho Federal de Psicologia (CFP) 2016. p. 75-80.

7. Anjos KF, Santos VC, Souzas R, Eugênio BG. Aborto e saúde pública no Brasil: reflexões sob a perspectiva dos direitos humanos. Saúde em Debate 2013; 37(98):504-515.

8. Organização Mundial de Saúde (OMS). Abortamento Seguro: Orientação Técnica e de Políticas para Sistemas De Saúde. Geneva: OMS; 2013.

9. Heilborn ML, Cabral CS, Brandão ER, Faro L, Cordeiro F, Azize RL. Itinerários abortivos em contextos de clandestinidade na cidade do Rio de Janeiro - Brasil. Cien Saude Colet 2012; 17(7):1699-1708.

10. Tornquist CS, Pereira SM, Benetti FJ. Usos e sentidos do Cytotec. Percepções sobre o uso do "comprimido" em um bairro popular de Florianópolis. In: Arend SMF, Assis GO, Motta FM, organizadores. Aborto e contracepção: histórias que ninguém conta. Florianópolis: Editora Insular; 2012. p. 173-206.

11. Portugal S. Para uma abordagem reticular do cuidado em saúde. Cien Saude Colet 2018; 23(10):3137-3139.

12. Teixeira RR. As dimensões da produção do comum e a saúde. Saúde e Sociedade 2015; 24(Supl. 1):27-43.

13. Diniz D, Medeiros M. Itinerários e métodos do aborto ilegal em cinco capitais brasileiras. Cien Saude Colet 2012; 17(7):1671-1681.

14. Castells M. A Sociedade em Rede: do Conhecimento à Política. In: Castells $\mathrm{M}$, Cardoso $\mathrm{G}$, organizadores. $A$ Sociedade em Rede - Do Conhecimento à Acção Política. Lisboa: Imprensa Nacional, Casa da Moeda, 2006: 17-30.

15. Whitten D. Vessel [Documentário] Direção. Espanha / Estados Unidos / Holanda / Irlanda / Polônia: Sovereignty Productions; 2014: $86 \mathrm{~min}$.

16. Aiken ARA, Gomperts R, Trussell J, Worell M, Aiken C. Requests for Abortion in Latin America Related to Concern about Zika Virus Exposure. N Engl J Med 2016; 375(4):396-398.

17. Hine C. Virtual Ethnography. London: SAGE Publications; 2000.

18. Miller D, Slater D. Etnografia on e offline: cibercafés em Trinidad. Horizontes Antropológicos 2004; 10(21):41-65. 
19. Ribeiro D. O que é lugar de fala? Belo Horizonte: Letramento; 2017. (Feminismos plurais).

20. Menezes G, Aquino EML. Pesquisa sobre o aborto no Brasil: avanços e desafios para o campo da saúde coletiva. Cad Saude Publica 2009; 25(Supl.):s193-204.

21. Instituto Brasileiro de Geografia e Estatística (IBGE). Pesquisa Nacional por Amostra de Domicílios (PNAD) - Acesso à Internet e à Televisão e Posse de Telefone Móvel Celular para Uso Pessoal. Rio de Janeiro: IBGE; 2014.

22. Martins AL, Mendonça LC. Dossiê Aborto: Mortes Preveníveis e Evitáveis. Belo Horizonte: Rede Feminista de Saúde; 2005.

23. Haber CD, Cravo MGAP. Perfil das mulheres processadas por aborto no Rio de Janeiro. In: Defensoria Pública do Estado do Rio de Janeiro, Coordenação de Defesa de Mulher dos Direitos Humanos, CEJUR. Entre a morte e a prisão: quem são as mulheres criminalizadas pela prática do aborto no Rio de Janeiro. Rio de Janeiro: Defensoria Pública Geral do Estado do Rio de Janeiro; 2018. p. 15-50.

24. Goes E. Enquanto houver racismo para as mulheres negras, o aborto sempre será inseguro, desumano e criminalizado. Caderno Sisterhood 2016; 1(1):105110 .

25. Ardaillon D. O lugar do íntimo na cidadania de corpo inteiro. Revista Estudos Feministas 1997; 5(2):376-388.

26. Motta FM. Não contra pra ninguém: o aborto segundo mulheres de uma comunidade popular urbana. In: Arend SMF, Assis GO, Motta FM, organizadores. Aborto e contracepção: histórias que ninguém conta. Florianópolis: Editora Insular; 2012. p. 97-136.

27. Scavone L. Dar a vida e cuidar da vida: feminismo e Ciências Sociais. São Paulo: Editora da UNESP, 2004.

28. Diniz D, Corrêa M, Squinca F, Braga KS. Aborto: 20 anos de pesquisas no Brasil. Cad Saude Publica 2009; 25(4):939-942.

29. Camurça S. 'Nós mulheres' e nossa experiência comum. Cadernos de Crítica Feminista 2007; 0(1):12-25.

30. Federici S. Feminism and the politics of the commons. Oakland: AK Press; 2010.

31. Soihet R. História das mulheres e história de gênero - um depoimento. Cadernos Pagu 1998; (11):77-87.

32. Rohden F. Ginecologia, gênero e sexualidade na ciência do século XIX. Horizontes Antropológicos 2002; 8(17):101-125.

Artigo apresentado em 30/05/2019

Aprovado em 07/08/2019

Versão final apresentada em 18/11/2019 